\title{
Goldbach: A New Conjecture
}

\section{Ivan Gondim Leichsenring*}

Apex Algoritmos, Barueri, Sao Paulo, Brasil

\section{Opinion}

Goldbach's letter to Euler, dated June 7, 1742, gave rise to the modern version of his conjecture, as currently widespread. primes

Every even integer greater than 2 can be written as the sum of 2

We are proposing an equivalent conjecture.

Any integer greater than 1 can be represented by the mean of 2 primes

Examples:

Prime $37=(31+43) \div 2$;

Even $38=(29+47) \div 2$;

Odd $39=(37+41) \div 2$.

Then we would have, for any positive integer $n>1$, the identity: 2 $\mathrm{n}=\mathrm{p}+\mathrm{q}$, with $\mathrm{p}$, q primes.

It is known that: $2 \mathrm{n}=(\mathrm{n}-\mathrm{k})+(\mathrm{n}+\mathrm{k})$ for any $\mathrm{k}$; in particular an integer.

And so we can have:

$\mathrm{p}=\mathrm{n}-\mathrm{k}$ and $\mathrm{q}=\mathrm{n}+\mathrm{k}$.

In this way, we obtain primes equidistant from $\mathrm{n}$, through index $\mathrm{k}$, which we call symmetry for the number $n$.

This symmetry, involving the integers:

$(\mathrm{n}-\mathrm{k})<\mathrm{n}$ and $(\mathrm{n}+\mathrm{k})>\mathrm{n}$.

Has as amplitude: $3 \bullet \bullet \bullet n \bullet \bullet 2 n-3$.

Below are several symmetries for the number 39 .

$5_{-34} 7_{-32} 11_{-28} 17_{-22} 19_{-20} 31_{-8} 37_{-2} 399_{0} 41_{2} 47_{8} 59_{20} 61_{22} 67_{28} 71_{32} 73_{34}$

Obviously, if $\mathbf{n}$ itself is prime, the result is trivial for $\mathrm{k}=0$; however, in our purpose we always adopt:

$$
\begin{aligned}
& \mathrm{k}>0, \\
& \mathrm{n}>3 \mathrm{e}, \\
& \mathrm{p} \neq \mathrm{q} .
\end{aligned}
$$

Simple, ordinary arithmetic mean. We distinguish odd integers from odd integers primes. If the number for which we seek symmetry is even the index is odd, and vice versa. When we considered the hypothesis, we verified the first 2097150 consecutive integers and the confirmation of the statement occurred. But it was not enough; we tried several other consecutive numbers (always being random the first of them) of greater magnitude, for example [1]:

32-bits integers:

$2326416308 \cdot \bullet 2326437251$

64-bits integers:

$10812083835233317544 \bullet \bullet 10812083835233361798$ 128-bits integers:

\section{0 •••}

313545261969434692888811456477964922750

256-bits integers:

6192320351375108084644961593402992759589707358556040597 6048239712178367757632 .••

6192320351375108084644961593402992759589707358556040597 6048239712178367757800 .

By analyzing $\mathrm{k}$, we observe that it is always very small with respect to $n$. For 2097150 integers, the maximum value of $\mathrm{k}$ found was 1722 . In random tests performed with 512-bit numbers, the highest value of $\mathrm{k}$ was 70038 , which turned out to be curious! The index is only 17 bits.

The next we see the number:

1312920071689103336635487768861320906735030946245083534 3836694081340406493202375322485753821651880624847198852520 $323171633499058898983581690280849216741069=$

(131292007168910333663548776886132090673503094624508353 4383669408134040649320237532248575382165188062484719885252 $0323171633499058898983581690280849216671031)+$

(131292007168910333663548776886132090673503094624508353 4383669408134040649320237532248575382165188062484719885252 $0323171633499058898983581690280849216811107) \div 2$.

We use the Rabin-Miller algorithm to find out if the numbers are primes. In view of the results with the first consecutive integers, we were not so rigorous in the subsequent investigations and the total iterations for the primality test were only 25 times for each prime. But, what is the guarantee that the result is always found? And another doubt has arisen: how can we assess the likelihood of finding this symmetry?

Just to fix an idea, let's examine the following problem: we have 20 perfect and identical spheres and two ideal roulettes, one to the left $\mathrm{L}-$ and one to the right $-\mathrm{R}-$, each with 36 numbered cells, which we will call the index [2].

We rotate the left roulette wheel and throw 11 of the spheres. We rotate the right roulette wheel and launch the remaining 9 spheres. What would be the probability of obtaining at least one match, so that any of the 11 cells occupied in roulette $L$, and any of the 9 cells occupied in roulette $\mathrm{R}$ had same index?

*Corresponding author: Ivan Gondim Leichsenring, Apex Algoritmos, Barueri, Sao Paulo, Brasil, Tel: 558007032111; E-mail: ivan@apex.eti.br

Received September 10, 2017; Accepted November 03, 2017; Published November 08, 2017

Citation: Leichsenring IG (2017) Goldbach: A New Conjecture. Ind Eng Manage 6 237. doi:10.4172/2169-0316.1000237

Copyright: @ 2017 Leichsenring IG. This is an open-access article distributed under the terms of the Creative Commons Attribution License, which permits unrestricted use, distribution, and reproduction in any medium, provided the original author and source are credited. 
For convenience only, we will investigate the inverse question: what would be the probability 朋 of no coincidence? That is, at the end, when the roulettes are stopped, none of the balls have the same index!

The reasoning: when all the cells of roulette $\mathrm{L}$ are occupied and we throw the first ball in roulette $\mathrm{R}$ we have 36 cells available. However, we do not want its index to match any of the 11 indexes occupied by the other roulette wheel [3].

The probability of this event is $25 \div 36$.

When we launch the 2nd sphere we already have a cell occupied and therefore one less option, so that this probability is $24 \div 35$.

Then, in this way, the possibilities are reduced to each launch and to the last sphere, the probability is $17 \div 28$.

To achieve the goal, the probability of no coincidence is obtained: 羽 $=(25 \div 36) \times(24 \div 35) \times \cdots \times(18 \div 29) \times(17 \div 28)$. It knowing the result, 羽 $=0.0217$.

We can now answer the first question: the probability of at least one coincidence is 0.9783 .

Roulettes with $\mathrm{N}$ cells and with $\mathrm{P}+\mathrm{Q}$ spheres require a better equation, since if the values involved are large the calculation becomes tedious, difficult or even impracticable.

We prefer to use 羽, $_{\mathrm{r}}$, the probability of not getting any matches, rather than the probability of obtaining at least one match, which is given by the complement of 犸 to 1 . And only 㖘 $_{\mathrm{r}}$ will be used here!

Impracticable: it seems simple to distinguish even numbers from odd! Just see the unit's digit. However, it is not immediate for a number of the order of a googol written in base 5 ! Note that $10_{5}$ is not divisible by 2 .

Formulating, we have:

羽 $=[(\mathrm{N}-\mathrm{P}) \mathrm{N}] \times[(\mathrm{N}-\mathrm{P}-1) \div(\mathrm{N}-1)] \times \cdots \times[(\mathrm{N}-\mathrm{P}-\mathrm{Q}+1) \div(\mathrm{N}-\mathrm{Q}+1)]$.

And the following combinatorial identity, for integers $a>b>m>0$, is useful:

$$
\begin{aligned}
\left.\mathbb{C}_{\left\{{ }_{m}\right.}^{b}\right\} \div & \left.\div \mathbb{C}_{{ }_{m}}^{a}\right\}=\{[b ! \div(b-m) !]\} \div\{[a ! \div(a-m) !]\} \\
& =[(b \div a)] \times[(b-1) \div(a-1)] \times \bullet \bullet \\
\cdots & \times[(b-m+1) \div(a-m+1)] .
\end{aligned}
$$

Thus, with our variables, if $\mathrm{N}>\mathrm{P}>\mathrm{Q}$ and $\mathrm{N}-\mathrm{P} \geq \mathrm{Q}$, we have:

$$
\text { 羽 }{ }_{\mathrm{r}}=\mathbb{C}\left\{{ }^{\mathrm{N}-\mathrm{P}}{ }_{\mathrm{Q}}\right\} \div \widetilde{C}\left\{\mathrm{~N}_{\mathrm{Q}}^{\mathrm{N}}\right\} .
$$

And, to illustrate, in the case of the roulettes we would have: $\mathbb{C}$ $\left\{{ }_{9}^{25}\right\} \mathbb{C}\left\{{ }_{9}^{36}\right\}$.

Returning to our conjecture, we will investigate what occurs with primes distributed between integers using the same previous modelfixing a certain number $\mathrm{n}$ and considering the amplitude of $\mathrm{N}$ integers: Smaller than $\mathrm{n}$ containing $\mathrm{P}$ primes and Larger than $\mathrm{n}$ containing $\mathrm{Q}$ primes.

We have already seen how to calculate the probability of not finding any pair of spheres under equivalent index and we have an analogous question, the primes being:

$$
\mathrm{p}=\mathrm{n}-\mathrm{k} \text { and } \mathrm{q}=\mathrm{n}+\mathrm{k} \text {. }
$$

If $\mathrm{N}$, and therefore $\mathrm{P}$ and $\mathrm{Q}$, are of high magnitudes it is difficult to obtain the probability as we did, because even if $\mathrm{N}$ is known, how do we know the value of $\mathrm{P}$ and $\mathrm{Q}$ ?
Firstly, we can use an artifice! It is not difficult to verify that:

$$
[(\mathrm{N}-\mathrm{P}) \div \mathrm{N}]>[(\mathrm{N}-\mathrm{P}-1) \div(\mathrm{N}-1)]>\bullet \bullet \bullet
$$

$\bullet \cdot>[(\mathrm{N}-\mathrm{P}-\mathrm{Q}+1) \div(\mathrm{N}-\mathrm{Q}+1)]$.

And, consequently, we can do:

$\mathrm{P}_{\mathrm{r}}=[(\mathrm{N}-\mathrm{P}) \div \mathrm{N}]^{\mathrm{Q}}$ considering that this value is greater than $\mathbb{C}_{\{\mathrm{N}-\mathrm{P}}$ $\mathrm{Q}\} \div \underset{\mathbb{C}}{\mathrm{r}}\left\{{ }_{\mathrm{Q}}^{\mathrm{N}}\right\}$.

Next, we know what the Prime Number Theorem (PNT) assures us:

$\Pi(\mathrm{x}) \approx \mathrm{x} \log (\mathrm{x})$.

For the factorial of very large numbers it is better to use the Stirling approximation.

PNT: The theorem describes the distribution of prime numbers between integers and was independently demonstrated by Jacques Hadamard and Charles Jean de la Vallée-Poussin in 1896, through the study of Bernhard Riemann's function $\zeta$. The theorem assures us that the number of primes smaller (or possibly equal) than $\mathrm{x}$ is proportional to the ratio of $\mathrm{x}$ to $\log _{\mathrm{e}}(\mathrm{x})[4]$.

This allows us to say, within the available amplitude, with $\mathrm{P} \geq \mathrm{Q}$ :

$$
\begin{array}{ll}
\mathrm{P} \approx \mathrm{N} \div \log (\mathrm{N}) & \text { primes }<\mathrm{n} \\
\mathrm{Q} \approx 2 \mathrm{~N} \div \log (2 \mathrm{~N})-\mathrm{N} \div \log (\mathrm{N}) & \text { primes }>\mathrm{n}
\end{array}
$$

We have:

羽 $=[1-(\mathrm{P} \div \mathrm{N})]^{\mathrm{Q}}$

And replacing $\mathrm{P}$ and $\mathrm{Q}$, we have:

$$
\text { 羽 }=\{1-[1 \div \log (\mathrm{N})]\}^{[2 \mathrm{~N} \div \log (2 \mathrm{~N})-\mathrm{N} \div \log (\mathrm{N})]} \text {. }
$$

For the conjecture to be valid we finally needed to demonstrate that 羽 tends to zero when $\mathrm{n}$ tends to infinity and then we are faced with an apparent paradox: the intuitive limit of function was not zero and calculations indicated that yes.

But, we continue, and despite the time required to calculate this limit, we can not obtain it; all attempts were fruitless.

However, using the Internet we have seen that the problem is already consecrated among academics and, in fact, the limit of the function is zero.

This is how we obtained the expected result, and thus, the probability of not getting any coincidence is:

$$
\operatorname{Lim}_{N \rightarrow \infty} \text { 羽 }_{r}=0 \text {. }
$$

That is, there will probably always be at least one coincidence.

Evaluating the first numbers was easy and much more we can get by simply computing exhaustively through continuous iterations.

But in view of what we have: a probabilistic calculation; could there be any $\mathrm{n}$ for which the conjecture fails, between the last one to be obtained and the infinite.

\section{References}

1. Yi Lu (2012) New Progress of Goldbach's Conjecture. National Academy Science Letters 35: 373-377.

2. Keming Z (1991) Fundamentals of number theory. Southwest China Normal University Press, Chongqing. 
Citation: Leichsenring IG (2017) Goldbach: A New Conjecture. Ind Eng Manage 6: 237. doi:10.4172/2169-0316.1000237

Page 3 of 3

3. Yi L (2007) An interesting problem discovered in the properties of even numbers. Nat Sci Res 12: 93-95
4. Weisstein, Eric W (2013) Goldbach Conjecture. MathWorld A Wolfram Web Resource. 